\title{
IDENTIFIKASI KELAYAKAN LAHAN BUDI DAYA IKAN DALAM KERAMBA JARING APUNG DENGAN APLIKASI SISTEM INFORMASI GEOGRAFIS DI TELUK PANGPANG, JAWA TIMUR
}

\author{
I Nyoman Radiarta, Adang Saputra, dan Bambang Priono
}

\begin{abstract}
ABSTRAK
Pemilihan lokasi merupakan suatu faktor kunci yang menentukan kesuksesan dan keberlangsungan dalam berbagai macam kegiatan budi daya perikanan. Penelitian ini memanfaatkan teknologi SIG untuk mengidentifikasi kelayakan lahan bagi budi daya KJA. Penelitian telah dilaksanakan di Teluk Pangpang pada bulan Juli dan September 2002. Penentuan stasiun pengamatan dilakukan secara acak dengan teknik sederhana. Data lapangan diklasifikasikan, kemudian dianalisis dengan metode pembobotan dan teknik tumpang susun dengan SIG. Hasil survai menunjukkan bahwa kondisi kualitas perairan (fisik, kimia, dan logam berat) masih dalam kisaran yang baik. Dari total area Teluk Pangpang 3.207 ha terdapat 991 ha yang berpotensi untuk kegiatan budi daya ikan dalam KJA, sisanya adalah daerah rataan lumpur yang pada saat surut cukup rendah dan daerah dengan kedalaman kurang dari $8 \mathrm{~m}$ mencapai 2.217 ha. Berdasarkan analisis SIG diperoleh lokasi seluas 240 ha yang ideal untuk pengembangan budi daya ikan dalam KJA.
\end{abstract}

\section{ABSTRACT: Identification of area suitability for marine fish cage culture using geographic information system at Pangpang Bay, East Java. By: I Nyoman Radiarta, Adang Saputra, and Bambang Priono}

Site selection is a key factor in any aquaculture operation, affecting both success and sustainability. GIS technique has been used to identify area suitability for marine fish cage culture. The research had been done at Pangpang Bay in July and September 2002. Simple random sampling was used to allocate sampling points. Field data were classiefied and then analyzed using weighting method and overlay technique with GIS application. Based on the survey, range of the water quality value generally is still good for mariculture activities. Pangpang Bay has total area of 3.207 ha, from this total area, only 991 ha that is potential for mariculture activities and the rest of 2,217 ha is mud areas especially dry during low tides and area with the depth less than $8 \mathrm{~m}$. Based on GIS analysis when it is overlaid among important parameters of water qualitiy the area of 240 ha is ideal for marine fish cage culture.

KEYWORDS: $\quad$ marine fish cage culture, area suitability, GIS, Pangpang Bay

\section{PENDAHULUAN}

Kegiatan budi daya laut dapat menghasilkan pangan, meningkatkan pendapatan, dan menyerap tenaga kerja; juga berkontribusi untuk diversifikasi produksi primer dan dapat mengurangi kegiatan perikanan tangkap (Scialabba, 1998; Ramelan, 1998). Produktivitas budi daya laut di suatu lokasi sangat dipengaruhi oleh meningkatnya permintaan akan lokasi dan sumber daya pesisir oleh kegiatan lainnya. Kompetisi pemanfaatan lahan ini tentunya akan meningkatkan degradasi mutu lingkungan yang ada. Kompetisi dalam pemanfaatan ruang dan sumber daya meliputi kegiatan: navigasi, konservasi pesisir/laut, daerah rawa dan mangrove, pertanian, penduduk dan kegiatan industri, aktivitas pelabuhan, pengembangan pariwisata, dan aktivitas lainnya. Semua kegiatan ini dapat menyebabkan berkurangnya akses dan kontrol bagi sumber daya perikanan. Perubahan dapat ditimbulkan baik oleh kegiatan perikanan itu sendiri maupun dari sektor lain yang mungkin pengaruhnya lebih besar. Sehubungan dengan kompetisi penggunaan lahan tersebut, kerusakan habitat perikanan yang mempengaruhi sektor perikanan akan sangat signifikan misalnya konversi daerah rawa dan mangrove oleh kegiatan pengembangan tambak dan pencemaran perairan oleh kegiatan industri maupun pariwisata.

Sehubungan dengan pengembangan akuakultur, dari sudut pandang ekonomi FAO Fisheries Department (1997) dikemukakan dua kategori ekternalitas yang perlu dipertimbangkan dan dikurangi. Pertama, eksternalitas yang ditimbulkan oleh kegiatan- 
kegiatan yang menciptakan kondisi yang tidak cocok untuk yang lainnya, seperti misalnya berbagai bentuk pencemaran atau dampak kegiatan manusia yang bersifat merusak sumber daya. Kedua, eksternalitas yang ditimbulkan oleh persaingan dalam akses ke sumber daya yang terbatas, misalnya air atau suatu ruas dari kawasan pesisir dan menjurus pada ketidakefisiensian ekonomi karena lebih banyak modal dan tenaga kerja yang diinvestasikan dan manfaat yang diperoleh lebih kecil.

Keberlanjutan usaha perikanan budi daya untuk jangka waktu yang panjang sangatlah penting untuk memperhatikan kondisi lingkungan sekitarnya yang mempunyai pengaruh yang kecil bagi kegiatan tersebut. Pemilihan lokasi merupakan langkah awal dan umumnya merupakan tahapan yang sangat penting untuk menciptakan perikanan budi daya yang berkelanjutan (Beveridge, 1996). Pemilihan lokasi yang salah akan menyebabkan kegiatan budi daya tidak berlangsung lama. Seperti dikemukakan oleh Ahmad (2001) bahwa perkembangan kegiatan budi daya laut di Indonesia masih banyak yang mengalami kesalahan dalam perencanaan, penyebabnya adalah kurangnya pengetahuan tentang lingkungan perairan yang tidak cocok bagi kegiatan budi daya laut maupun adanya data parameter kualitas air yang tidak sesuai di lokasi tersebut. Agar kegiatan budi daya laut dapat berhasil, sangatlah penting untuk menempatkan kegiatan budi daya laut tersebut dengan benar. Lokasi yang benar menurut Meaden \& Do Chi (1996) dan Lovatelli (1988), dapat berdasarkan sudut pandang mikro dan makro. Contohnya lokasi yang baik kemungkinan berada sepanjang 100 kilometer di daerah pesisir, atau lokasi yang baik terdapat di perairan teluk, goba, atau estuarin. Kesesuaian lingkungan untuk budi daya laut dipengaruhi oleh beberapa faktor di antaranya: karakteristik biofisik lokasi (biologi, hidrologi, lokasi, meteorologi, tanah, dan kualitas air); karakter spesifik dari biota yang dibudidayakan; metode budi daya (konstruksi dan desain, level produksi, dan operasi); kemampuan akses untuk pinjaman dan informasi; serta teknologi yang sesuai.

Saat ini penerapan dan pengembangan dari strategi penentuan lokasi budi daya perikanan (zonasi) telah dibuat konsepnya, namun teknik dan metode untuk memperoleh hasil yang diinginkan masih dalam tahapan pengembangan (Pe'rez et al., 2003 after Clark \& Hosting, 1986). Telah banyak data dan informasi tentang pemilihan lokasi perikanan budi daya khususnya faktor lingkungan yang sudah dikumpulkan, namun sangat sedikit penelitian yang menganalisis data spasial. Sehubungan dengan hal ini, sistem informasi geografis (SIG) merupakan pilihan teknologi yang sangat relevan dalam mengerjakan tugas tersebut. SIG merupakan sistem yang khusus dirancang untuk mengerjakan data, baik itu spasial ataupun posisi geografis (Burrough \& McDonnell, 1998). SIG mempunyai beberapa keuntungan dalam hal pengembangan perikanan budi daya. Tidak hanya menghasilkan inventarisasi visual yang meliputi fisik, biologi, dan karakteristik ekonomi lingkungan, tapi mempunyai kemampuan membuat model dalam rangka menyusun peta kesesuaian untuk aktivitas yang berbeda. Pemanfaatan SIG dalam bidang perikanan budi daya dirasakan masih sangat sedikit, hanya beberapa penelitian yang dilaporkan dalam literatur. Kapetsky et al. (1987) untuk pertama kalinya mengaplikasikan SIG di bidang perikanan budi daya yang berhubungan dengan kelayakan lahan budi daya tambak udang di Costa Rica. Penelitian ini diyakini sebagai awal dari pemanfaatan SIG dalam bidang perikanan budi daya.

Pada saat sekarang ini, aplikasi SIG dalam bidang perikanan budi daya meliputi: (1) pemilihan lokasi berdasarkan perbedaan komoditas meliputi ikan, udang, kekerangan, kerang mutiara, rumput laut, dan kima (Kapetsky et al., 1988; Ross et al., 1993); berdasarkan perbedaan cakupan lokasi penelitian meliputi lokal, regional, nasional, dan kontinental (Kapetsky et al., 1987; Meaden \& Kapetsky, 1991); pendugaan dampak kegiatan budi daya perikanan terhadap lingkungan (Pe'rez et al., 2000), dan konflik di antara penggunaan sumber daya pesisir ( $P$ e'rez et al., 2003).

Tujuan penelitian ini adalah melakukan analisis kelayakan lahan yang diperuntukkan guna pengembangan budi daya laut, terutama guna kegiatan budi daya ikan dalam keramba jaring apung dengan memanfaatkan teknologi SIG. Hasil dari penelitian ini diharapkan menjadi masukan bagi pemerintah daerah untuk mengalokasikan pengembangan budi daya laut dan sebagai bahan penyusunan rencana tata ruang wilayah.

\section{BAHAN DAN METODE}

Penelitian ini telah dilakukan pada bulan Juli dan September 2002 dengan mengambil lokasi di Teluk Pangpang (Gambar 1). Teluk Pangpang terletak di bagian ujung tenggara Provinsi Jawa Timur. Perairan ini secara administratif masuk ke dalam Kabupaten Banyuwangi yang membujur dari $114^{\circ} 19^{\prime}-114^{\circ} 24$ Bujur Timur dan $8^{\circ} 26^{\prime}-8^{\circ} 32^{\prime}$ Lintang Selatan. Teluk Pangpang dengan luasan mencapai 3.207 ha merupakan perairan yang berpotensi bagi pengembangan budi daya laut, karena perairannya yang relatif tenang dan terlindung. Pengertian budi daya laut ini khususnya untuk budi daya ikan dalam keramba jaring apung (KJA). 
Metode yang dipakai dalam penelitian ini adalah metode survai yang dirancang berdasarkan sistem informasi geografis (SIG). Penentuan titik pengamatan dirancang dengan simple random sampling (Clark \& Hosking, 1986; Burrough \& McDonnell, 1998) yang diterapkan untuk penentuan titik pengamatan di lapangan. Penentuan posisi dengan menggunakan alat GPS (Global Positioning System). Sebanyak 38 titik pengamatan kualitas perairan telah dikumpulkan. Sebaran titik sampling dan ekosistem di lokasi penelitian dapat dilihat pada Gambar 1.

Data yang dikumpulkan dalam penelitian ini terdiri atas data primer dan data sekunder. Data primer yang dikumpulkan adalah data kualitas perairan yang meliputi: parameter fisik (luasan, kedalaman, suhu air, kecerahan, kecepatan arus), kimia (salinitas, pH, DO), logam berat: besi $(\mathrm{Fe})$, seng $(\mathrm{Zn})$, timbal $(\mathrm{Pb})$, dan kromium $(\mathrm{Cr})$. Data sekunder berupa peta dasar lokasi penelitian. Peta dasar ini bersumber dari peta rupa bumi skala 1:25.000 (lembar: 1707-421; 1707-422; 1707-143; dan 1707-144) keluaran Bakosurtanal. Informasi yang diambil dari peta rupa bumi ini meliputi: garis pantai, sungai, jaringan transportasi (jalan), sebaran penduduk, mangrove, dan kegiatan perikanan yang ada (tambak). Data yang dikumpulkan ini merupakan data masukan untuk analisis spasial. Diagram alur analisis spasial penentuan lokasi budi daya KJA dapat dilihat pada Gambar 2.

Data kualitas perairan yang dikumpulkan dari lapangan berupa titik pengamatan yang penyebarannya mewakili lokasi penelitian. Untuk menganalisis secara spasial, titik-titik tersebut terlebih dahulu harus dilakukan interpolasi, yang merupakan suatu metode dalam pengolahan data titik menjadi area (polygon). Cara interpolasi titik menjadi area menggunakan metode Nearest Neighbor (Burrough \& McDonnell, 1998; Morain, 1999). Dari hasil interpolasi masing-masing parameter kualitas perairan yang diperoleh kemudian disusun dalam bentuk peta tematik. Luasan perairan yang layak bagi kegiatan budi daya KJA dihasilkan setelah seluruh data parameter utama pembobotan dalam bentuk peta tematik dibuat (ditumpangsusunkan). Dari hasil interpolasi masingmasing parameter kualitas perairan yang diperoleh kemudian ditentukan lokasi yang layak bagi budi daya KJA berdasarkan nilai ideal untuk budi daya KJA. Nilai ideal kualitas perairan yang digunakan untuk pemilihan lokasi berdasarkan Ahmad et al. (1995), Beveridge (1996), Imanto et al. (1995), Ismail et al. (1998), dan Mayunar et al. (1995), dapat dilihat pada Tabel 1.

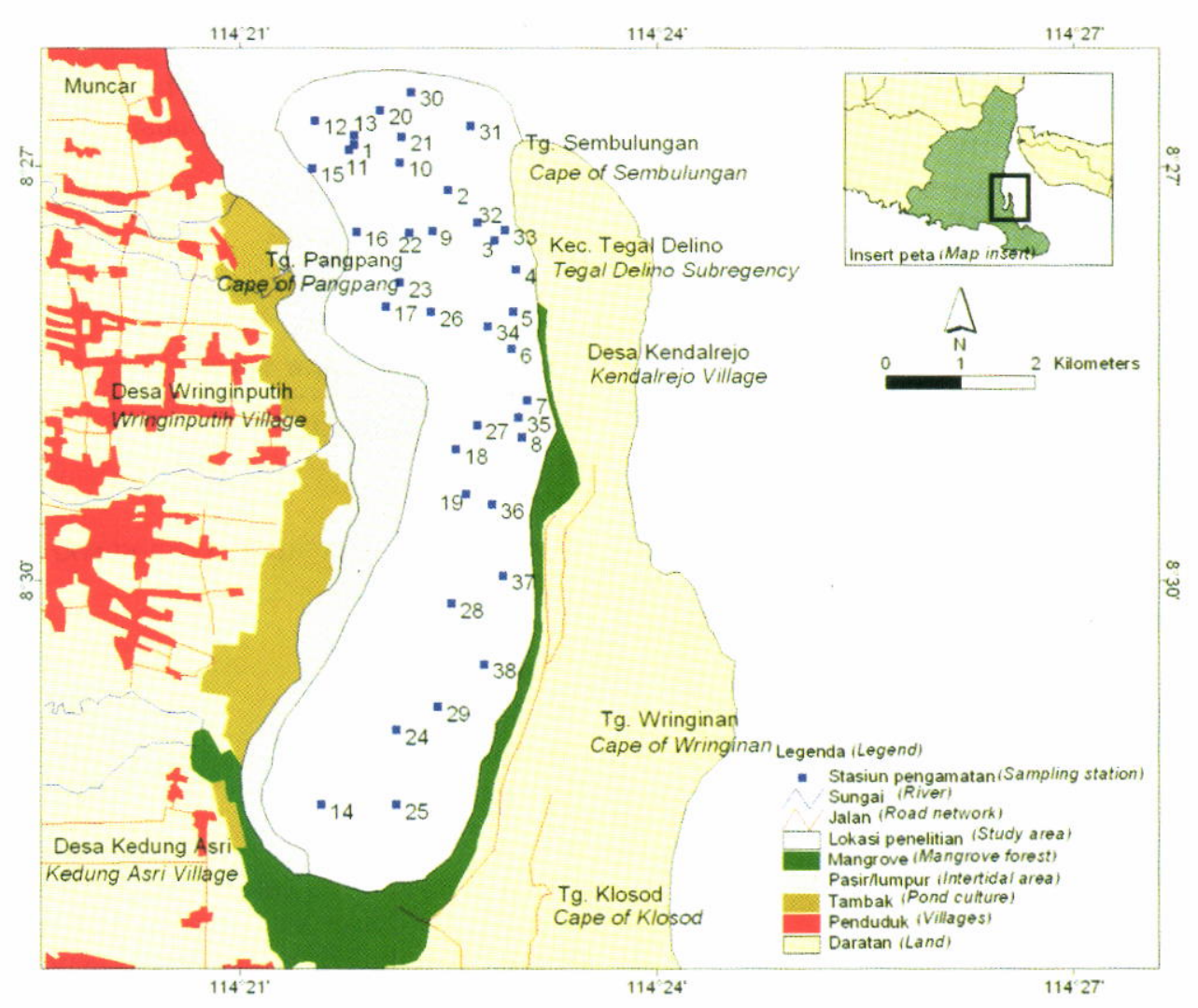

Gambar 1. Tampilan umum lokasi penelitian di Teluk Pangpang dan distribusi lokasi pengamatan kualitas perairan

Figure 1. General features of Pangpang Bay and distribution of water quality sampling points 


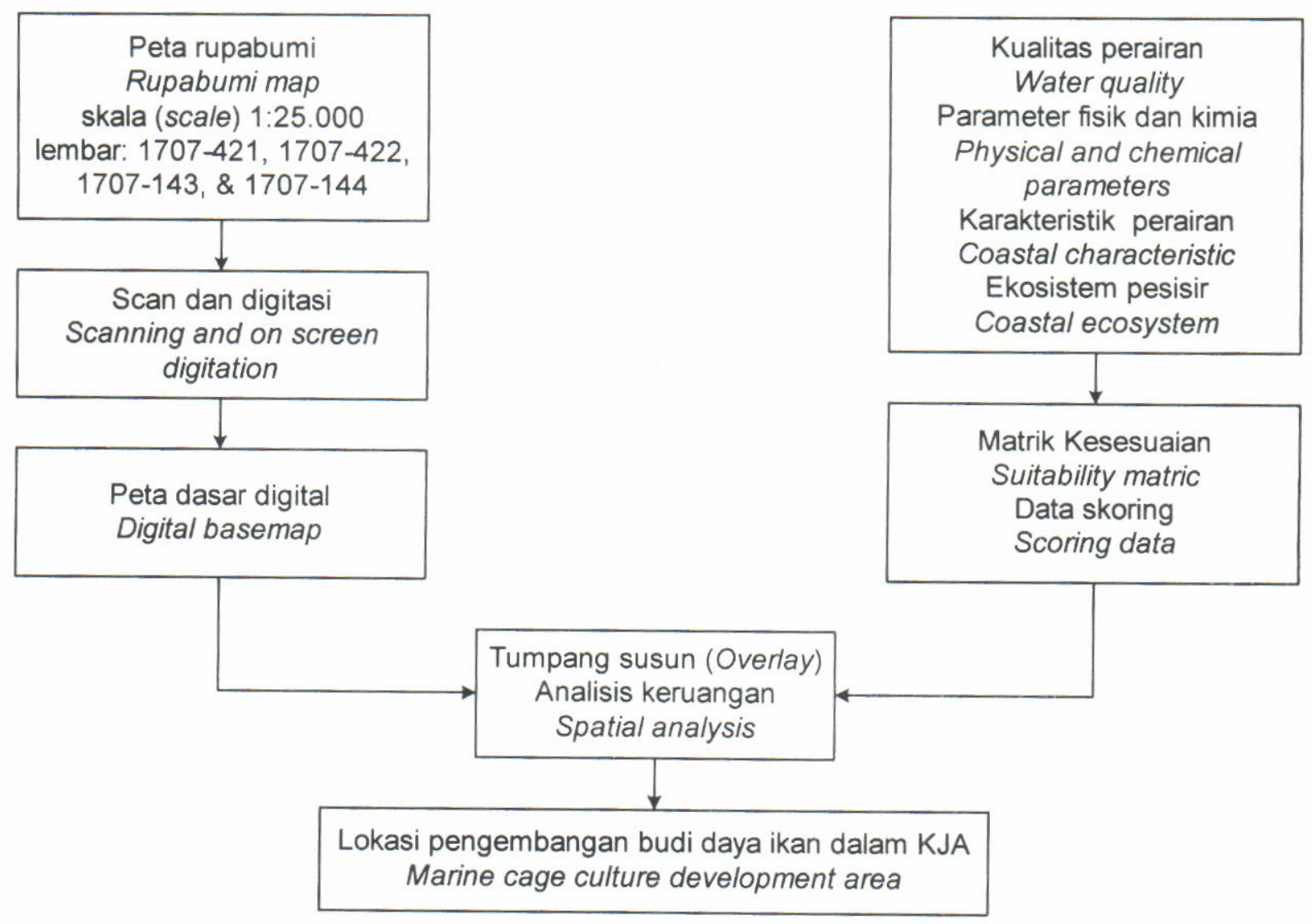

Gambar 2. Diagram alur penentuan lokasi budi daya ikan keramba jaring apung

Figure 2. Flow chart of site selection method for marine fish cage culture

Tabel 1. Nilai ideal parameter kualitas perairan pemilihan lokasi budi daya keramba jaring apung

Table 1. Water quality ideal value for site selection of marine fish cage

\begin{tabular}{|c|c|c|}
\hline $\begin{array}{l}\text { Parameter } \\
\text { Parameter }\end{array}$ & $\begin{array}{c}\text { Satuan } \\
\text { Unit }\end{array}$ & $\begin{array}{l}\text { Nilai ideal } \\
\text { Ideal value }\end{array}$ \\
\hline Morfologi (Morphology) & & Terlindung (Closed) \\
\hline Kedalaman (Water depth) & $\mathrm{m}$ & $8-15$ \\
\hline Arus (Water current) & $\mathrm{cm} / \mathrm{dt}$ & $0.1-0.5$ \\
\hline Substrat dasar (Sediment) & & Pasir dan pecahan karang (Sand and rubble \\
\hline Kecerahan (Transparency) & $\mathrm{m}$ & $>3$ \\
\hline Salinitas (Salinity) & ppt & $30-35$ \\
\hline Pencemar (Pollutan) & & Tidak ada (Free) \\
\hline Keamanan (Security) & & Aman (Secure) \\
\hline Keterjangkauan (Accessibility) & & Mudah (Easy) \\
\hline Tenaga kerja (Availability of labour) & & Mudah (Easy) \\
\hline
\end{tabular}

\section{HASIL DAN BAHASAN}

\section{Kondisi Umum Lokasi}

Teluk Pangpang sangat dipengaruhi oleh adanya proses sedimentasi. Proses sedimentasi yang berlangsung intensif berasal dari Sungai Setail dan sungai lainnya yang mengalir dari arah barat menjadikan teluk ini semakin dangkal. Pada saat air surut, di sisi barat teluk merupakan rataan lumpur dengan lebar sekitar $\pm 3 \mathrm{~km}$ membujur utara-selatan sepanjang $\pm 10 \mathrm{~km}$. Kawasan mangrove di Teluk Pangpang ditemukan sepanjang pantai timur sampai selatan yang mencapai luasan 490 ha. Pemanfaatan kawasan ini lebih intensif karena merupakan tempat berkembangnya biota potensial seperti kerang- 
kerangan dan kepiting bakau serta daerah penangkapan anak-anak ikan dan udang.

Teluk Pangpang sangat erat sekali dengan kegiatan masyarakat di sekitarnya meliputi Pelabuhan Perikanan Muncar, aktivitas nelayan tangkap, dan pabrik-pabrik pengolahan ikan di sekitar pelabuhan tersebut. Dengan adanya fasilitas jalan, sarana transportasi, serta faktor lainnya meningkatkan kegiatan perekonomian masyarakat sekitarnya. Dampak langsung dari kondisi ini akan meningkatkan pencemaran lingkungan, salah satunya adalah terhadap budi daya di tambak yaitu semakin menurunnya produktivitas tambak. Terlihat dari beberapa lokasi tambak yang sudah dibangun tidak dioperasikan karena dalam setiap siklusnya persentase keberhasilan lebih sedikit dibandingkan dengan kegagalannya.

Berdasarkan hasil analisis pasang surut di lokasi perairan Meneng, Kabupaten Banyuwangi
(Dinas Hidro Oseanografi, 2002) untuk bulan Juli dan September Agustus 2002 (Gambar 3) menunjukkan kondisi pasang surut di lokasi penelitian tergolong tipe campuran yang cenderung ke harian ganda yaitu terjadi dua kali pasang dan surut (Nontji, 1993; Anonim, 2001). Kondisi pasang surut ini sangat mempengaruhi luasan area yang dapat digunakan untuk kegiatan budi daya laut secara umum (KJA, rumput laut, dan ain-lain). Pada saat surut terrendah, total area yang tergenang air adalah 2.576 ha atau $80 \%$ dari total area Teluk Pangpang, sisanya 631 ha (20\%) berupa daerah dangkal/kering yang saat surut terrendah sebagian lokasinya merupakan rataan lumpur. Jika dilihat dari stratifikasi kedalaman perairan di mana untuk budi daya ikan dalam KJA kedalaman minimum disyaratkan $8 \mathrm{~m}$, maka luasan daerah yang berpotensi untuk budi daya ikan dalam KJA adalah mencapai 991 ha.
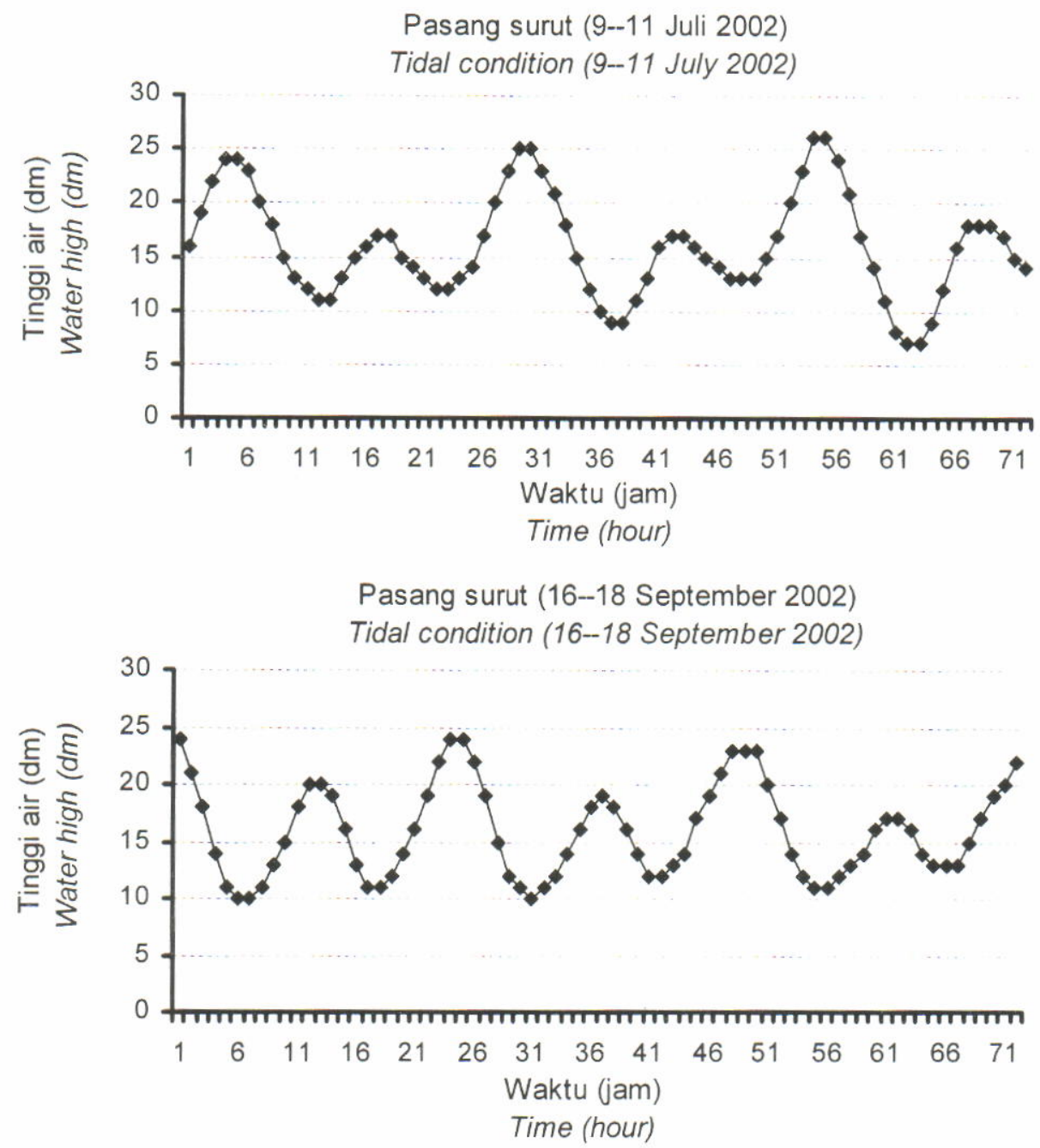

Gambar 3. Kondisi pasang surut stasiun perairan Meneng pada bulan Juli dan Oktober (Sumber: Dinas Hidro Oseanografi, 2002)

Figure 3. Tidal condition at Meneng station on July and October (Source: Dinas Hidro Oseanografi, 2002) 


\section{KONDISI PERAIRAN}

Sebanyak 38 titik pengamatan telah dikumpulkan selama survai lapangan dilakukan. Pengambilan data kualitas perairan dilakukan pada pukul 09.30-15.00 WIB. Data kisaran kualitas perairan (parameter fisik dan kimia) hasil pengamatan disajikan pada Tabel 2.

Secara umum kualitas perairan permukaan terutama parameter fisik dan kimia di 38 titik pengamatan masih dalam batas toleransi kegiatan budi daya laut. Adanya proses sedimentasi yang disebabkan oleh beberapa sungai yang menuju ke Teluk Pangpang cukup mempengaruhi kondisi kualitas perairan teluk, di antaranya kedalaman dan kecerahan perairan. Kedalaman perairan berkisar antara 0,5-20 m. Kondisi ini masih cukup baik untuk kegiatan budi daya ikan. Beverage (1996) melaporkan bahwa untuk budi daya $\mathrm{KJA}$, jarak antara KJA dengan dasar perairan berkisar antara $4-5 \mathrm{~m}$. Kecerahan di perairan teluk makin menurun pada bagian dalam teluk. Hal ini sangat dipengaruhi oleh adanya proses sedimentasi. Untuk kecerahan yang cukup tinggi ditemukan di mulut teluk yang mencapai $5 \mathrm{~m}$. Untuk kegiatan budi daya KJA tingkat kecerahan haruslah lebih besar dari $3 \mathrm{~m}$. Suhu perairan dengan kisaran $24^{\circ} \mathrm{C}-27^{\circ} \mathrm{C}$ merupakan kisaran yang cukup rendah, namun masih dalam kategori layak bagi kegiatan budi daya laut. Untuk budi daya ikan, suhu dengan kisaran $27^{\circ} \mathrm{C}-32^{\circ} \mathrm{C}$ merupakan kisaran yang baik dan layak (Mayunar et al., 1995). Tinggi gelombang dan kecepatan arus berdasarkan hasil pengukuran mempunyai kisaran nilai antara $10-75 \mathrm{~cm}$ dan $7-35 \mathrm{~cm} / \mathrm{dt}$. Kisaran nilai tersebut masih dalam kategori yang baik untuk kegiatan budi daya. Dengan adanya Semenanjung Sembulungan menyebabkan perairan ini cukup terlindung. Hal ini berimplikasi terhadap kondisi gelombang dan kecepatan arus di perairan teluk, yang umumnya masih dalam kisaran yang baik.
Parameter kimia hasil pengukuran lapangan umumnya masih dalam kategori yang baik untuk kegiatan budi daya biota laut. Salinitas perairan yang terukur berkisar antara $35-40$ ppt. Kisaran salinitas ini masih dalam kategori yang layak bagi kegiatan budi daya ikan. Kandungan oksigen (DO) dalam perairan sangat penting bagi sintasan ikan tersebut. Untuk kegiatan budi daya kandungan DO yang diinginkan adalah $>5 \mathrm{mg} / \mathrm{L}(\mathrm{KLH}, 2004)$. Dari hasil pengukuran menunjukkan bahwa DO berkisar antara $4,2-8,5 \mathrm{mg} / \mathrm{L}$, hal ini berarti masih dalam kisaran yang baik untuk kegiatan budi daya ikan.

Selain data kualitas air, beberapa data logam berat juga dikumpulkan meliputi: besi (Fe), timbal $(\mathrm{Pb})$, kromium ( $\mathrm{Cr}$ ), dan seng ( $\mathrm{Zn}$ ). Penentuan jenis logam berat ini berdasarkan pertimbangan bahwa di sekitar perairan Banyuwangi banyak terdapat industri, di antaranya pengalengan ikan sehingga dikhawatirkan adanya limbah logam berat dari industri tersebut. Selain industri pengalengan ikan, terdapat tempat-tempat pengolahan ikan dan buangan dari kegiatan ini mempengaruhi kandungan bahan organik perairan. Secara alamiah, unsur-unsur logam berat terdapat di mana-mana dalam konsentrasi sangat rendah. Konsentrasi tersebut akan meningkat sejalan dengan bertambahnya aktivitas manusia seperti: perindustrian, pertambangan, dan pertanian serta limbah perkotaan dan buangan lainnya yang banyak mengandung logam. Mercuri $(\mathrm{Hg})$ merupakan jenis logam berat yang paling berbahaya diikuti dengan cadmium, seng, timbal, dan kromium (Clark, 1977 dalam Mayunar et al., 1995). Dari hasil analisis kandungan logam berat, masih dalam batas-batas normal, disajikan pada Tabel 3 .

Hasil analisis terhadap logam berat yang terlarut dalam air di lokasi penelitian untuk besi berkisar antara $0,027-0,108 \mathrm{mg} / \mathrm{L}$; timbal 0,01-0,23 mg/L; kromium $0,02-0,06 \mathrm{mg} / \mathrm{L}$; dan seng $0,01-0,98 \mathrm{mg} /$

Tabel 2. Kisaran nilai kualitas air di Teluk Pangpang, Kabupaten Banyuwangi

Table 2. Value range of water quality at Pangpang Bay, Banyuwangi Regency

\begin{tabular}{lll}
\hline \multicolumn{1}{c}{$\begin{array}{c}\text { Parameter } \\
\text { Parameters }\end{array}$} & \multicolumn{1}{c}{$\begin{array}{c}\text { Satuan } \\
\text { Unit }\end{array}$} & \multicolumn{1}{c}{$\begin{array}{c}\text { Kisaran nilai } \\
\text { Value range }\end{array}$} \\
\hline Fisik (Physical) & & \\
Suhu (Temperature) & ${ }^{\circ} \mathrm{C}$ & $24--27(25.17 \pm 0.89)$ \\
Kecerahan (Transparency) & $\mathrm{m}$ & $0.4--5.0(2.26 \pm 1.48)$ \\
Kecepatan arus (Water current) & $\mathrm{cm} / \mathrm{dt}$ & $7--35(19.60 \pm 7.69)$ \\
Kedalaman (Water depth) & $\mathrm{m}$ & $0.5--20(9.24 \pm 6.45)$ \\
Tinggi gelombang (Wave high) & $\mathrm{cm}$ & $10--75(30.86 \pm 14.93)$ \\
\hline Kimia (Chemical) & & \\
pH & & $8.1--8.7(8.53 \pm 0.15)$ \\
Salinitas (Salinity) & $\mathrm{ppt}$ & $35--40(37.43 \pm 1.72)$ \\
Oksigen terlarut (Dissolve oxygen) & $\mathrm{mg} / \mathrm{L}$ & $4.2--8.5(6.28 \pm 1.19)$ \\
\hline
\end{tabular}


Tabel. 3. Kandungan logam berat (mg/L) di Teluk Pangpang, Kabupaten Banyuwangi Table 3. Heavy metal consentration at Pangpang Bay, Banyuwangi Regency

\begin{tabular}{crrrr}
\hline $\begin{array}{c}\text { Stasiun } \\
\text { Station }\end{array}$ & \multicolumn{1}{c}{$\begin{array}{c}\mathrm{Fe} \\
\text { Iron }\end{array}$} & $\begin{array}{c}\mathrm{Pb} \\
\text { Timbale }\end{array}$ & $\begin{array}{c}\mathrm{Cr} \\
\text { Cromium }\end{array}$ & $\begin{array}{c}\text { Zn } \\
\text { Zinc }\end{array}$ \\
\hline 11 & 0.07 & 0.23 & 0.06 & 1.46 \\
18 & 0.027 & 0.05 & 0.02 & 0.20 \\
20 & 0.027 & 0.01 & 0.02 & 0.01 \\
22 & 0.108 & 0.01 & 0.03 & 0.12 \\
24 & 0.036 & 0.16 & 0.02 & 1.98 \\
26 & 0.057 & 0.11 & 0.05 & 1.20 \\
31 & 0.036 & 0.06 & 0.03 & 0.49 \\
33 & 0.04 & 0.08 & 0.05 & 0.81 \\
34 & 0.048 & 0.07 & 0.02 & 0.92 \\
\hline Simpangan baku (Standar deviation) & $\mathbf{0 . 0 5}$ & $\mathbf{0 . 0 9}$ & $\mathbf{0 . 0 3}$ & $\mathbf{0 . 8 0}$ \\
\hline Ratan (Average) & $\mathbf{0 . 0 3}$ & $\mathbf{0 . 0 7}$ & $\mathbf{0 . 0 2}$ & $\mathbf{0 . 6 7}$ \\
\hline
\end{tabular}

L menunjukkan masih diambang batas normal bagi kehidupan ikan. Menurut KLH (2004), baku mutu timbal, kromium, dan seng masing-masing adalah 0,008 mg/L; 0,01 mg/L; 0,005 mg/L; dan 0,05 mg/L.

Data kualitas air yang mempunyai pengaruh dominan dan relatif tidak mengalami perubahan yang cepat dilakukan interpolasi untuk mengetahui pola spasial dari data tersebut. Gambar 4 menampilkan beberapa data parameter fisik perairan hasil interpolasi. Data yang perubahannya cukup dinamis (contohnya: suhu, salinitas, arus) dibuat hanya untuk mendapatkan gambaran pola sebaran spasial pada saat pengambilan data tersebut. Sehingga dapat membantu dalam menganalisis kelayakan lahan budi daya ikan.

\section{Status Peruntukan Lahan}

Kegiatan perikanan umumnya telah berkembang di sekitar teluk maupun dalam kawasan Teluk Pangpang. Kegiatan perikanan ini meliputi perikanan budi daya dan tangkap. Perikanan budi daya yang telah berkembang dan dapat dijumpai di sekitar kawasan teluk yaitu telah perikanan tambak seluas 521 ha (hasil analisis peta rupa bumi) yang terbentang mulai dari Tanjung Pangpang sampai di Desa Kedung Sari dan dalam kawasan ditemukan beberapa unit KJA (Tabel 4). Di Teluk Pangpang terdapat 8 unit/kelompok budi daya keramba jaring apung meliputi keramba percontohan Dinas Kelautan dan Perikanan dan perorangan. Komoditas yang dibudidayakan terdiri atas kerapu tikus dan lobster. Pada saat penelitian lapang dilakukan, KJA yang berlokasi di Kecamatan Tegal Delimo difungsikan untuk menampung lobster.

Dilihat dari perkembangannya, kegiatan budi daya di sekitar teluk kurang pesat walaupun dari hasil yang diperoleh tidak ada kendala. Dari data budi daya lobster di perairan tersebut, dipelihara lobster ukuran $\pm 50 \mathrm{~g} /$ ekor dalam jaring $1,5 \times 1,5 \times 2,5 \mathrm{~m}^{3}$ dengan kepadatan 100 ekor/jaring dan lama pemeliharaan $5-6$ bulan sehingga menghasilkan lobster ukuran pasar \pm 200 g/ekor. Pakan yang diberikan berupa udang dan kepiting. Untuk budi daya ikan dalam KJA umumnya pakan yang diberikan adalah pakan rucah dan udang. Ketersediaan pakan ini sangat didukung oleh keberadaan tempat pelelangan ikan yang relatif dekat dengan lokasi budi daya.

Berdasarkan hasil wawancara dengan pembudi daya ikan setempat teridentifikasi adanya kendala untuk pengembangan budi daya ikan dalam KJA, yaitu masalah pasok benih. Umumnya benih yang digunakan, baik itu kerapu tikus maupun lobster, masih mengandalkan penangkapan dari alam sehingga dari faktor jumlah dan kesinambungan tidak terjamin. Hal ini menjadi penyebab lambatnya perkembangan budi daya di lokasi tersebut. Namun dengan kemampuan teknologi perbenihan (hatchery) sekarang ini yang telah dilakukan di beberapa instansi pemerintah di antaranya Balai Besar Riset Perikanan Budidaya Laut, Gondol dan Loka Budidaya Laut Situbondo, masalah ketersediaan benih bukan merupakan kendala utama. Kedua instansi ini telah berhasil memproduksi benih ikan kerapu yaitu kerapu macan dan kerapu bebek/ tikus dan merupakan pemasok benih kerapu untuk kegiatan budi daya ikan laut di Indonesia.

Selain kegiatan budi daya laut, di dalam kawasan teluk ditemukan juga adanya bagan, baik itu bagan apung maupun bagan tancap serta beberapa unit sero. Ketersediaan alat tangkap bagan dapat menjadi sumber bagi ketersediaan pakan ikan rucah untuk ikan yang dibudidayakan, sedangkan sero dapat 


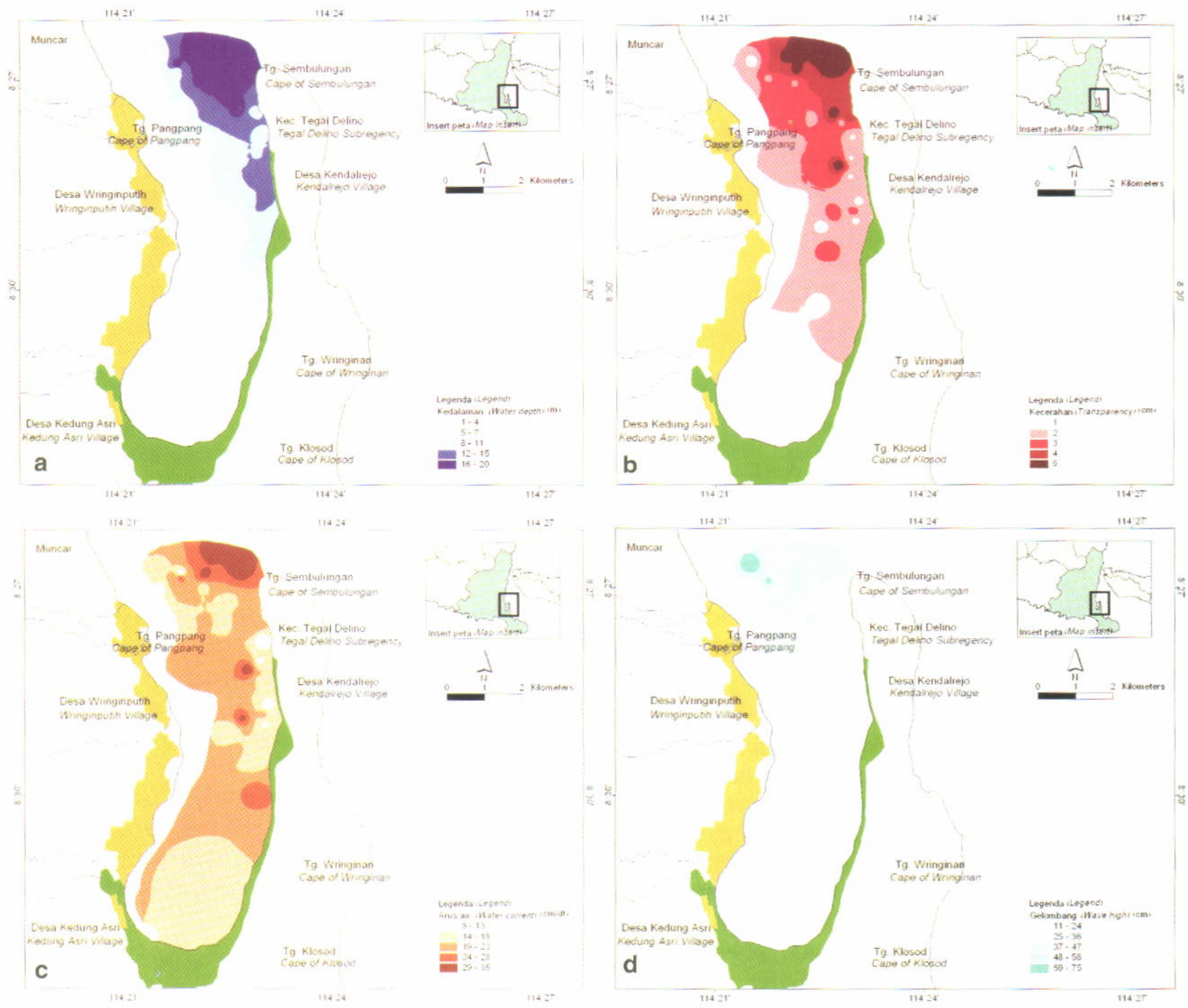

Gambar 4. Sebaran spasial kualitas perairan di Teluk Pangpang, Kabupaten Banyuwangi: (a) kedalaman, (b) kecerahan, (c) kecepatan arus, dan (d) gelombang

Figure 4. Spatial distribution of water quality at Pangpang Bay, Banyuwangi Regency: (a) water depth, (b) transparency, (c) water current, and (d) wave

Tabel 4. Jenis kegiatan budi daya pantai di sekitar Teluk Pangpang

Table 4. Aquaculture activities around Pangpang Bay

\begin{tabular}{lc}
\hline \multicolumn{1}{c}{ Lokasi (Location) } & $\begin{array}{c}\text { Kegiatan budi daya perikanan } \\
\text { Existing aquaculture }\end{array}$ \\
\hline Desa Wringinputih (Wringinputih Villages) & Tambak (Pond culture) \\
Tanjung Pangpang (Cape of Pangpang) & Tambak (Pond culture) \\
Desa Kedung Asri (Kedung Asri Villages) & Tambak (Pond culture) \\
Tanjung Sembulungan (Cape of Sembulungan) & KJA (Marine fish cage) \\
Kecamatan Tegal Delimo (Tegal Delimo Sub Regency) & KJA (Marine fish cage) \\
\hline
\end{tabular}

membantu untuk mengumpulkan benih dari alam. Gambaran umum kegiatan perikanan yang berkembang di sekitar kawasan teluk dapat dilihat pada Gambar 5.

\section{Lokasi Pengembangan Budi Daya KJA}

Dari hasil skoring dan pembobotan analisis kualitas air serta didukung oleh berbagai pertimbangan non 


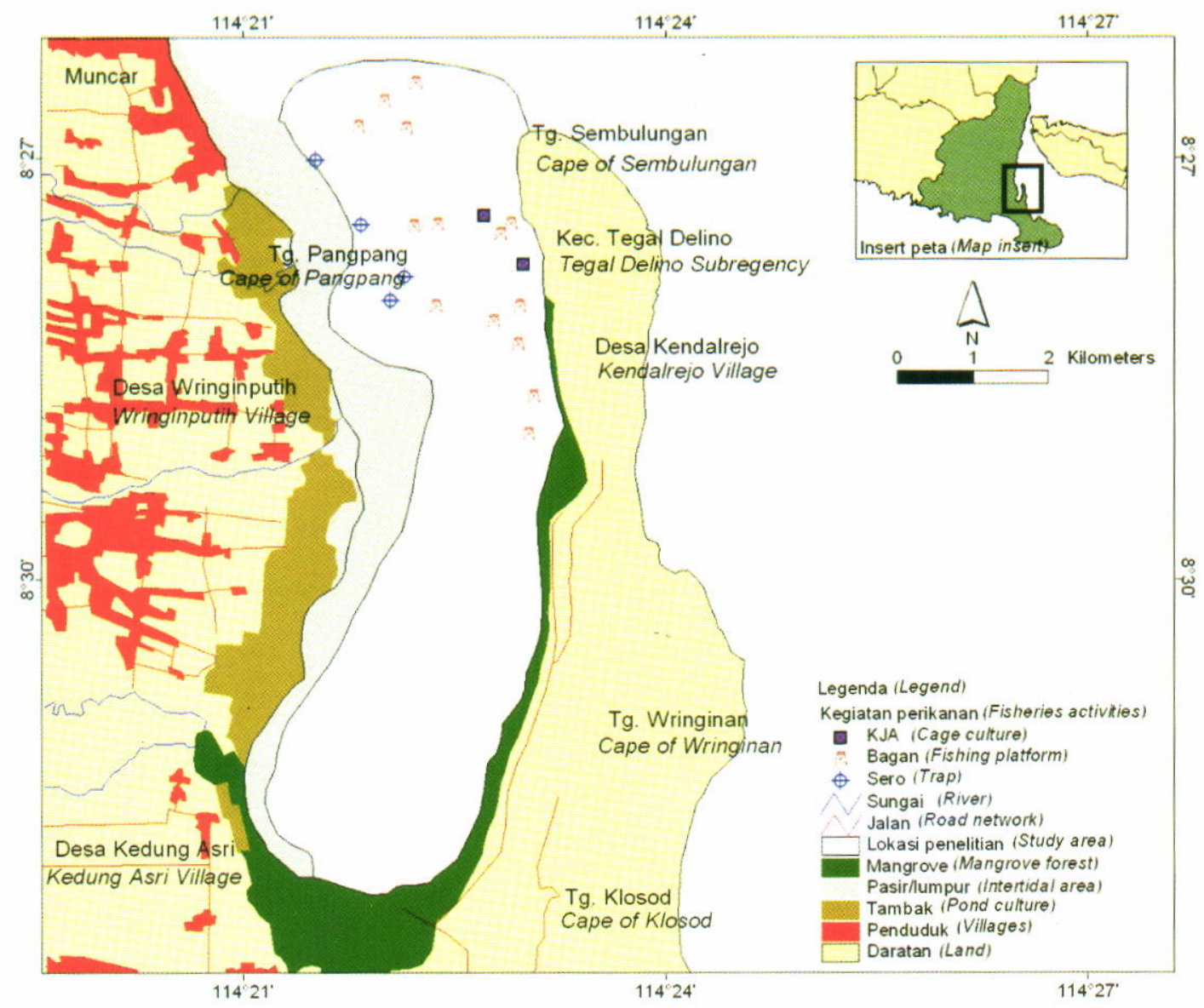

Gambar 5. Kegiatan perikanan yang sudah ada di lokasi penelitian Figure 5. Existing fisheries activities at research location

teknis (kondisi lokasi penelitian dan status peruntukan lahan) maka tingkat kelayakan lahan untuk budi daya ikan dalam KJA dapat diidentifikasi dan disajikan dalam bentuk peta tematik. Total luasan daerah penelitian di Teluk Pangpang adalah 3.207 ha, dari total luasan tersebut lokasi ideal pengembangan budi daya ikan dalam KJA adalah seluas 240 ha ke arah mulut pantai. Luasan tersebut hanya $24 \%$ dari total area potensial di Teluk Pangpang (991 ha). Peta tematik kelayakan lahan budi daya ikan dalam KJA dapat dilihat pada Gambar 6. Dari hasil analisis ini menunjukkan bahwa lokasi ideal pengembangan terletak di ujung teluk di mana sirkulasi air yang keluar masuk teluk masih baik serta jauh dari pengaruh sedimentasi yang terjadi di perairan teluk.

Untuk pengembangan usaha yang berkelanjutan, maka potensi yang ada sekiranya tidak dimanfaatkan seluruhnya, namun harus disediakan area yang fungsinya sebagai penyangga. Teluk Pangpang dengan luasan ideal pengembangan 240 ha dapat dimanfaatkan untuk budi daya ikan dalam KJA seluas $24 \mathrm{ha}$. Ini berarti area yang dimanfaatkan hanya sebesar $10 \%$ (Hanafi et al., 2001). Dengan pertimbangan bahwa 1 ha lahan budi daya dapat dimanfaatkan secara efektif untuk 100 unit KJA ( $10 \%$ dari luasan ideal), di mana 1 unit KJA terdiri atas 4 keramba dengan ukuran per keramba 1,5 $x 1,5 \times 2,5 \mathrm{~m}^{3}$. Menurut Imanto (2000), jika 1 unit KJA yang terdiri atas 4 keramba dengan ukuran $2,5 \times 2,5 \times$ $3,5 \mathrm{~m}^{3}$ maka untuk 1 ha lahan budi daya dapat dimanfaatkan secara efektif untuk 40 unit KJA serta padat tebar yang optimum mencapai $20 \mathrm{ekor} / \mathrm{m}^{3}$ dengan ukuran benih 7-10 $\mathrm{g}(3-4 \mathrm{~cm})$.

\section{KESIMPULAN}

Proses sedimentasi yang berasal dari beberapa sungai mempengaruhi kondisi Teluk Pangpang. Pada saat air surut di sisi barat teluk merupakan rataan lumpur. Selain itu kondisi pasang surut ini sangat mempengaruhi luasan area yang dapat digunakan untuk kegiatan budi daya laut. Pada saat surut terendah, total area yang berpotensi untuk budi daya laut adalah sebesar 991 ha atau sekitar 31\% dari total area Teluk Pangpang.

Kondisi kualitas perairan (parameter fisik, kimia, dan logam berat) di lokasi penelitian masih dalam kriteria yang baik untuk kegiatan budi daya laut. Dari 


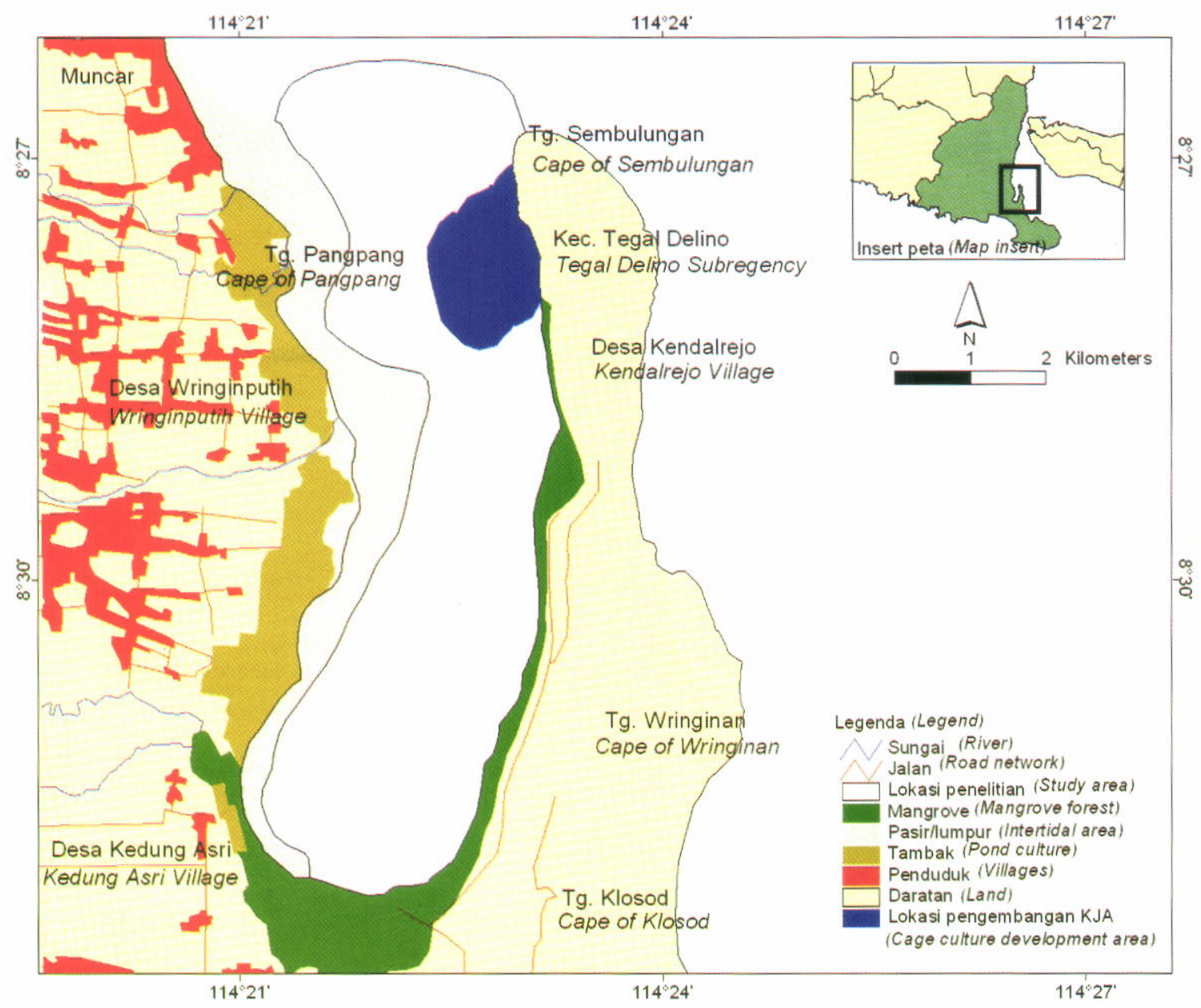

Gambar 6. Peta kelayakan lahan budi daya ikan dalam keramba jaring apung Figure 6. Suitability area map for fish culture (cage culture)

hasil skoring dan pembobotan analisis kualitas air diperoleh luasan yang ideal bagi pengembangan budi daya ikan sebesar 240 ha $(24 \%$ dari total area potensial di Teluk Pangpang). Dengan hanya memanfaatkan $10 \%$ dari luasan yang sangat layak tersebut, ini berarti untuk budi daya ikan area yang dapat dimanfaatkan seluas 24 ha.

\section{UCAPAN TERIMA KASIH}

Pada kesempatan ini penulis mengucapkan terima kasih kepada semua anggota tim, dari Pusat Riset Perikanan Budidaya dan Balai Penelitian Perikanan Air Tawar, Instalasi Riset Budidaya Ikan Hias Air Tawar-Depok, dan Loka Riset Pemacuan Stok Ikan-Jatiluhur yang telah membantu pelaksanaan penelitian ini.

\section{DAFTAR PUSTAKA}

Ahmad, T. 2001. Analisis Pengembangan Sea Farming di Indonesia. Warta Penelitian Perikanan Indonesia, 7(1): 9-14.
Ahmad, T., A. Rukyani, dan A. Wijono. 1995. Teknik budi daya laut dengan keramba jaring apung. Dalam Sudradjat et al. (Eds.). Prosiding Temu Usaha Pemasyarakatan Teknologi Keramba Jaring Apung Bagi Budi Daya Laut. Puslitbang Perikanan, Badan Litbang Pertanian, p. 69-87.

Anonim. 2001. Studi Pengembangan Potensi Wilayah Pantai Banyuwangi. Bappeda Kabupaten Banyuwangi, Pusat Studi Sumberdaya dan Teknologi Kelautan-UGM, $142 \mathrm{pp}$.

Beveridge, M.C.M. 1996. CageAqua-culture (Eds. $\left.2^{\text {nd }}\right)$. Fishing News Books LTD. Farnham, Surrey, England, $352 \mathrm{pp}$.

Burrough, P.A. and R.A. Mc Donnell. 1998. Principle of Geographical Information Systems. Oxford University Press, $327 \mathrm{pp}$.

Clark, W.A.V. and P.L. Hosking. 1986. Statistical Methods for Geographers. John Wiley \& Sons, Inc., 513 pp.

Dinas Hidro Oseanografi. 2002. Daftar Pasang Surut Kepulauan Indonesia. Jakarta, $637 \mathrm{pp}$.

FAO Fisheries Department. 1997. Aquaculture Development. FAO Technical Guidelines for Responsible Fisheries. No. 5, Rome, 40 pp. 
Hanafi, A., Tarunamuli, A. Rachman, dan T. Ahmad. 2001. Penataan ruang Teluk Pegametan di Kecamatan Gerokgak, Bali untuk pengembangan sea farming. Dalam Sudradjat et al. (Ed.) Teknologi Budi Daya Laut dan Pengembangan Sea Farming di Indonesia. Puslitbang Eksplorasi Laut dan Perikanan, p. 57-69.

Imanto, P.T. 2000. Budidaya ikan laut. Workshop Pengelolaan Sumberdaya Perikanan Berbasis Komunitas 20-22 November 2000, Lombok Timur, $19 \mathrm{pp}$.

Imanto, P.T., N. Listyanto, dan B. Priono. 1995. Desain dan kontruksi keramba jaring apung untuk budi daya ikan laut. Dalam Sudradjat et al. (Ed.). Prosiding Temu Usaha Pemasyarakatan Teknologi Keramba Jaring Apung bagi Budi Daya Laut. Puslitbang Perikanan, Badan Litbang Pertanian, p. 216-230.

Ismail, W., S.E. Wardoyo, dan B. Priono. 1998. Lokasilokasi potensial bagi panti benih terapung ikan karang di selatan P. Bintan dan Karimun Jawa. J. Pen. Per. Indonesia, 4(1): 36-46.

Kapetsky, J.M., L. McGregor, and H. Nanne. 1987. A Geographical Information System and Satellite Remote Sensing to Plan for Aquaculture Development: A FAO-UNEP/GRID Cooperative Study in Costa Rica. FAO Fisheries Technical Paper, 287: 51 pp.

Kapetsky, J.M., Hill. J.M. and Worthy, L. Dorsey. 1988. A Geographical Information System for Catfish Farming Development. Aquaculture, 68: 311-320.

KLH. 2004. Keputusan Menteri Negara Kependudukan dan Lingkungan Hidup. No. No. 51 tahun 2004, tanggal 8 April 2004 tentang Baku Mutu Air Laut. Kementerian Lingkungan Hidup, Jakarta, 11 pp.

Lovatelli, A. 1988. Site selection for mollusc culture. Workshop on GIS Application in Aquaculture 5--23 December, AIT, Bangkok, Thailand, 17 pp.

Meaden, G.J. and T. Do Chi. 1996. Geographical information systems: application to marine fisheries. FAO Fisheries Technical Paper. No. 356. Rome, FAO, $335 \mathrm{pp}$.

Meaden, G.J. and J.M. Kapetsky. 1991. Geographical information systems and remote sensing in inland fisheries and aquaculture. FAO Fisheries Technical Paper. No. 318. Rome, FAO, 262 pp.

Morain, S. 1999. GIS Solution in Natural Resource Management: Balancing the Technical-Political Equation. On Word Press. USA, 361 pp.

Mayunar, R. Purba, dan P.T. Imanto. 1995. Pemilihan lokasi untuk usaha budi daya ikan laut. Dalam Sudradjat et al. (Eds.). Prosiding Temu Usaha Pemasyarakatan Teknologi Keramba Jaring Apung bagi Budi Daya Laut. Puslitbang Perikanan, Badan Litbang Pertanian, p. 179-189.

Nontji, A. 1993. Laut Nusantara. Penerbit Djambatan, $362 \mathrm{pp}$.

Pe'rez, O.M., T.C. Telfer, and L.G. Ross. 2003. Use of GIS-based models for integrating and developing marine fish cages within the tourism industry in tenerife (Canary Island). Coastal Management, 31: 355-366.

Pe'rez, O.M., T.C. Telfer, M.C.M. Beveridge, and L.G. Ross. 2000. Geographical Information Systems (GIS) as a simple tool to aid modelling of particulate waste distribution at marine fish cage sites. Estuarine, Coastal, and Shelf Science, 54: 761-768.

Pe'rez, O.M., L.G. Ross, T.C. Telfer, and L.M. del Campo Barquin. 2003. Water quality requirements for marine fish cage site selection in tenerife (Canary Islands): predictive modelling and analysis using GIS. Aquaculture, 224: 51-68.

Ramelan, S.H. 1998. Pengembangan Budi daya Ikan Laut di Indonesia. Dalam Sudradjat et al. (Eds.). Prosiding Seminar Teknologi Perikanan Pantai, 67 Agustus 1998. Puslitbang Perikanan, p. 59-79.

Ross, L.G., E.A. Mendoza, Q.M., and M.C.M. Beveridge. 1993. The application of geograpical information systems to Site Selection for Coastal Aquaculture: An Example Based on Salmonid Cage Culture. Aquaculture, 112(2-3): 165-178.

Scialabba, N. (Ed.). 1998. Integrated Coastal Area Management and Agriculture, Forestry and Fisheries. FAO Guideline. Environment and Natural Resources Service, FAO, Rome, $256 \mathrm{pp}$. 
